\title{
"Our complication rates are lower than theirs": Statistical critique of heart valve comparisons
}

\author{
Gary L. Grunkemeier, PhD \\ YingXing $\mathrm{Wu}, \mathrm{MD}$
}

From Providence Health System, Portland,
Ore.
Received for publication Jan 28, 2002; re-
visions requested April 1,2002 ; revisions
received July 10, 2002; accepted for publi-
cation July 18, 2002 .
Address for reprints: Gary Grunkemeier,
PhD, 9155 SW Barnes, No. 33, Portland,
OR 97225 (E-mail: ggrunkemeier@
providence.org).
J Thorac Cardiovasc Surg 2003;125:
$290-300$
Copyright $@ 2003$ by The American Asso-
ciation for Thoracic Surgery
0022-5223/2003 $\$ 30.00+0$
doi:10.1067/mtc. 2003.53
Objectives: From the widely differing complication rates published for every heart valve, is it possible to determine a true rate for each valve and to compare the rates of two different valves? We investigated this question for the two most popular bileaflet valves.

Methods: Aortic valve data were abstracted from 14 St Jude Medical (St Jude Medical Inc, Minneapolis, Minn; 33,125 patient-y) and 11 Carbomedics (Sulzer Carbomedics Inc, Austin, Tex; 19,141 patient-y) series, and mitral valve data were abstracted from 11 St Jude Medical (21,553 patient-y) and 8 Carbomedics (8368 patient-y) series. Regression analysis was used to accommodate heterogeneity among rates with the same valve model, to estimate hazard ratios and 95\% confidence intervals for the valve model effect, and to incorporate other series-level risk factors.

Results: Most of the complication rates with both valve models exhibited significant heterogeneity. For thromboembolism and bleeding, the relative risks for valve model were not significantly different from unity. Valve thrombosis rates exhibited less heterogeneity: the Carbomedics valve had a lower rate in the aortic position (hazard ratio $0.2,95 \%$ confidence interval 0.1-0.6) and a higher rate in the mitral position (hazard ratio 1.9, 95\% confidence interval 1.0-3.8).

Conclusions: Unlike simple weighted averages of valve complication rates, regression methods can incorporate heterogeneity related to center effects and allow for inclusion of other risk factors. Thromboembolism and bleeding rates were not significantly different with St Jude Medical and Carbomedics valves. Valve thrombosis appeared to differ between the two valves, but the absolute differences in rates were small. Because of the variability among rates with the same valve, statistical comparisons must be interpreted cautiously.

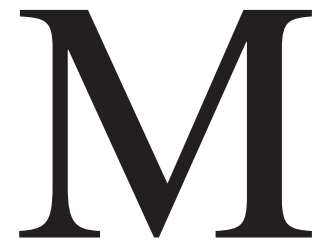

ost currently used mechanical heart valve prostheses have complication rates in the same clinical range, because those with extreme rates are eventually discarded. This clinical range is still wide, however, approximately $0.5 \%$ to $3.5 \%$ per year for aortic valve thromboembolism, for example, and one may ask, "What is the true rate for a particular valve? and "Which valve has the lowest rate?" Because of the variability observed from one study to another with the same prosthesis, a single observational study obviously cannot give the definitive answer. A review of many published, good quality studies may provide our best possibility of answering these questions. To illustrate, we selected the two most successful bileaflet valves, St Jude Medical (St Jude Medical Inc, Minneapolis, Minn) and Carbomedics (Sulzer Carbomedics Inc, Austin, Tex) and performed comparisons of thromboembolism, valve thrombosis, and bleeding rates in both the aortic and mitral positions. 


\section{Material and Methods \\ Clinical Material}

From sources identified by MEDLINE searches of the Englishlanguage journals, we selected aortic and mitral valve series published in the last 10 years with at least 400 patient-y of follow-up. This amount of follow-up conforms to the minimum requirements for Food and Drug Administration marketing approval of a new heart valve prosthesis. ${ }^{1}$ We used only articles that claimed conformance to either the original ${ }^{2}$ or the current ${ }^{3}$ guidelines for reporting and that had at least $95 \%$ completeness of follow-up, as the guidelines require. There was some inconsistency in the reporting of linearized rates. Most reports considered late events only, but it was often difficult to determine this for certain. Some other data limitations are described in Appendix 1.

From each published series we extracted by position (aortic or mitral) the linearized event rates, the components of the rates (number of events and total patient-years), and some potential risk factors that may affect the rates, including follow-up completeness, mean follow-up time, and longest follow-up time. If there was a decrease in risk with time, then series with longer follow-ups would be at an advantage. Inclusion of mean follow-up as a potential risk factor allowed us to consider this possibility. Patient age and gender were also collected but often were not given separately by valve position. Other potential risk factors abstracted were the journal (which was converted to the journal's impact factor), year of publication, number of valves, whether late events only were reported, and whether major events only were reported (for thromboembolism and bleeding).

\section{Statistical Methods}

"Linearized" rates, which assume that the risk (hazard) is constant with time, are used to summarize many time-related complications of heart valve replacement. For some complications, such as tissue valve failure, this assumption is clearly inappropriate because the hazard for failure increases with time. For several other complications, however, including thromboembolism, valve thrombosis, and bleeding, the assumption of a constant hazard rate is considered an acceptable approximation. The Food and Drug Administration has formulated objective performance criteria for new heart valve approvals that are based on linearized rates. A practical advantage of linearized rates is that most studies provide them. If not, the rate can be easily computed from the number of events and the total follow-up years by simple division (Rate $=100 \times$ Events/Year) to provide events per 100 valve-y, usually given as percent per patient-year or percent per year.

A convenient statistic for expressing the relationship between two linearized rates, for example thromboembolism with two heart valve models, is their ratio, called the relative risk or more specifically the hazard ratio (HR). If the two risks are equal, HR equals 1 ; the further HR is from unity, the greater is the valve model effect. The $95 \%$ confidence interval (CI) gives the range of values that are consistent with the observed data. There is a relationship between hypothesis testing and $95 \% \mathrm{CI}$ estimation. If the two rates are significantly different $(P<.05)$, then the $95 \% \mathrm{CI}$ does not include 1 . Conversely, if the rates are not significantly different, the $95 \%$ CI does include 1 . Because they are intrinsically related, we tended to emphasize the estimation $(95 \% \mathrm{CI})$ approach instead of the hypothesis testing ( $P$ value) approach. The $95 \% \mathrm{CIs}$ for individual linearized rates were calculated with a method suggested by Cox. ${ }^{4}$

Given several studies of the same valve model, one might be tempted to compute a weighted mean linearized rate (the sum of all events divided by the sum of all follow-up years) for each valve model and use these weighted averages to compute $95 \%$ CIs and to compare valve models. If the rates vary significantly among series with the same valve, however, then directly comparing the weighted averages will produce $95 \%$ CIs and $P$ values that are too small, because the extra variability among series is not accounted for. In this case a regression approach that accommodates diversity among series and adjusts the $95 \%$ CIs and $P$ values appropriately should be used. If the factors that cause this heterogeneity can be identified, they can be adjusted for in a Poisson regression analysis. If such variables cannot be identified, or if they do not sufficiently account for the heterogeneity among series, then a regression method that allows for heterogeneity among the rates with each valve model can be used. We used the negative binomial distribution, a generalization of the Poisson distribution (see Appendix 2 for details). These regression models provide an estimate of the HR for valve model adjusted for within-model heterogeneity and can be used to examine the simultaneous effects of other potential risk factors.

\section{Results}

Table 1 summarizes the information extracted from reports of aortic St Jude Medical valves, ${ }^{5-18}$ and Table 2 contains the information for aortic Carbomedics valves. ${ }^{6,19-28}$ Figures 1 through 3 contain comparison plots of the linearized rates separated by aortic valve model for thromboembolism, valve thrombosis, and bleeding, respectively. Table 3 summarizes the information extracted from reports of mitral St Jude Medical valves, ${ }^{7,8,11-16,18,29,30}$ and Table 4 contains the information for mitral Carbomedics valves. ${ }^{19,20,22,24-26,28,31}$ Figures 4 through 6 contain comparison plots of the linearized rates separated by mitral valve model for thromboembolism, valve thrombosis, and bleeding, respectively. Note that in most cases the rates vary widely for each valve model and do not appear to cluster about a central value for either model. Although we provide weighted averages (pooled values) at the bottoms of Tables 1 through 4, we therefore did not use these rates directly for analyses. For example, we did not compute $95 \%$ CIs for them, nor did we use their ratio to compute an HR. Instead, we let the regression do this, adding in the appropriate variability.

\section{Valve Model Comparisons}

Of the 12 groups of linearized rates $(3$ events $\times 2$ positions $\times 2$ valve models), all displayed significant $(P<.05)$ heterogeneity (Table 5) except for two of the valve thrombosis groups. Interestingly, these latter two groups had the fewest numbers of events. Negative binomial regression was used for all six valve model comparisons ( 3 events $\times 2$ positions). Table 5 contains the summary and comparison statistics. The HRs for the effect of the Carbomedics valve 
TABLE 1. St Jude Medical aortic valves

\begin{tabular}{|c|c|c|c|c|c|c|c|c|c|c|c|c|}
\hline \multirow[b]{3}{*}{ Series } & \multirow[b]{3}{*}{ Reference } & \multirow[b]{3}{*}{ Valves } & \multicolumn{4}{|c|}{ Follow-up } & \multirow{2}{*}{\multicolumn{2}{|c|}{ Thromboembolism }} & \multirow{2}{*}{\multicolumn{2}{|c|}{ Thrombosis }} & \multirow{2}{*}{\multicolumn{2}{|c|}{ Bleeding }} \\
\hline & & & \multirow{2}{*}{$\begin{array}{c}\text { Complete } \\
(\%)\end{array}$} & \multirow{2}{*}{$\begin{array}{c}\text { Mean } \\
\text { (y) }\end{array}$} & \multirow{2}{*}{$\begin{array}{l}\text { Longest } \\
\text { (y) }\end{array}$} & \multirow{2}{*}{$\begin{array}{l}\text { Total } \\
\text { (pt-y) }\end{array}$} & & & & & & \\
\hline & & & & & & & Events & Rate $(95 \% \mathrm{CI})$ & Events & Rate $(95 \% \mathrm{CI})$ & Events & Rate $(95 \% \mathrm{CI})$ \\
\hline A & 5 & 73 & 100 & 7 & 10 & 535 & 5 & $0.9(0.4-2.0)$ & & & 12 & $2.3(1.2-3.8)$ \\
\hline B & 6 & 149 & 96 & 4 & 7 & 608 & 8 & $1.3(0.6-2.5)$ & 0 & $0.0(0.0-0.4)$ & 25 & $4.1(2.7-6.0)$ \\
\hline C & 7 & 611 & 98 & 3 & 10 & 1,605 & 19 & $1.2(0.7-1.8)$ & 3 & $0.2(0.1-0.5)$ & 14 & $0.9(0.5-1.4)$ \\
\hline$D$ & 8 & 275 & 97 & 6 & 13 & 1,640 & 10 & $0.6(0.3-1.1)$ & 0 & $0.0(0.0-0.2)$ & 16 & $1.0(0.6-1.5)$ \\
\hline $\mathrm{E}$ & 9 & 270 & 100 & 6 & 16 & 1,654 & 18 & $1.1(0.7-1.7)$ & 0 & $0.0(0.0-0.2)$ & 21 & $1.2(0.8-1.9)$ \\
\hline $\mathrm{F}$ & 10 & 412 & 100 & 4 & 10 & 1,800 & 18 & $1.0(0.6-1.5)$ & & & 22 & $1.2(0.8-1.8)$ \\
\hline G & 11 & 194 & 96 & 10 & 15 & 1,843 & 37 & $2.0(1.4-2.7)$ & 3 & $0.2(0.0-0.4)$ & & \\
\hline $\mathrm{H}$ & 12 & 425 & 98 & 4 & 12 & 1,852 & 25 & $1.4(0.9-2.0)$ & 1 & $0.1(0.0-0.3)$ & 2 & $0.1(0.0-0.3)$ \\
\hline I & 13 & 204 & 100 & 10 & 10 & 1,969 & 73 & $3.7(2.9-4.6)$ & 0 & $0.0(0.0-0.1)$ & 33 & $1.7(1.2-2.3)$ \\
\hline J & 14 & 418 & 97 & 6 & 16 & 2,376 & 49 & $2.1(1.5-2.7)$ & 6 & $0.3(0.1-0.5)$ & 64 & $2.7(2.1-3.4)$ \\
\hline $\mathrm{K}$ & 15 & 578 & 100 & 4 & 13 & 2,441 & 59 & $2.4(1.8-3.1)$ & 2 & $0.1(0.0-0.3)$ & 42 & $1.7(1.3-2.3)$ \\
\hline $\mathrm{L}$ & 16 & 666 & 97 & 6 & 20 & 3,881 & 97 & $2.5(2.0-3.0)$ & 12 & $0.3(0.2-0.5)$ & 78 & $2.0(1.6-2.5)$ \\
\hline $\mathrm{M}$ & 17 & 694 & 100 & 6 & 18 & 4,502 & 53 & $1.2(0.9-1.5)$ & 2 & $0.0(0.0-0.1)$ & 24 & $0.5(0.4-0.8)$ \\
\hline $\mathrm{N}$ & 18 & 773 & 95 & 8 & 15 & 6,419 & 54 & $0.8(0.6-1.1)$ & 16 & $0.2(0.1-0.4)$ & 61 & $1.0(0.7-1.2)$ \\
\hline Total & & 5742 & & & & 33,125 & 525 & 1.58 & 45 & 0.15 & 414 & 1.32 \\
\hline
\end{tabular}

TABLE 2. Carbomedics aortic valves

\begin{tabular}{|c|c|c|c|c|c|c|c|c|c|c|c|c|}
\hline \multirow[b]{3}{*}{ Series } & \multirow[b]{3}{*}{ Reference } & \multirow[b]{3}{*}{ Valves } & \multicolumn{4}{|c|}{ Follow-up } & \multirow{2}{*}{\multicolumn{2}{|c|}{ Thromboembolism }} & \multirow{2}{*}{\multicolumn{2}{|c|}{ Thrombosis }} & \multirow{2}{*}{\multicolumn{2}{|c|}{ Bleeding }} \\
\hline & & & \multirow{2}{*}{$\begin{array}{c}\text { Complete } \\
(\%)\end{array}$} & \multirow{2}{*}{$\begin{array}{c}\text { Mean } \\
\text { (y) }\end{array}$} & \multirow{2}{*}{$\begin{array}{l}\text { Longest } \\
\text { (y) }\end{array}$} & \multirow{2}{*}{$\begin{array}{l}\text { Total } \\
\text { (pt-y) }\end{array}$} & & & & & & \\
\hline & & & & & & & Events & Rate (95\% CI) & Events & Rate $(95 \%$ CI) & Events & Rate $(95 \%$ Cl) \\
\hline 0 & 19 & 209 & 97 & 2 & 5 & 522 & 16 & $3.1(1.8-4.9)$ & 0 & $0.0(0.0-0.5)$ & 10 & $1.9(1.0-3.4)$ \\
\hline$P$ & 6 & 139 & 97 & 4 & 7 & 587 & 9 & $1.5(0.8-2.8)$ & 0 & $0.0(0.0-0.4)$ & 19 & $3.2(2.0-5.0)$ \\
\hline 0 & 20 & 239 & 99 & 4 & 8 & 928 & 22 & $2.4(1.5-3.5)$ & 0 & $0.0(0.0-0.3)$ & 14 & $1.5(0.9-2.5)$ \\
\hline $\mathrm{R}$ & 21 & 361 & 98 & 3 & 6 & 937 & 11 & $1.2(0.6-2.0)$ & 0 & $0.0(0.0-0.3)$ & 12 & $1.3(0.7-2.2)$ \\
\hline S & 22 & 359 & 98 & 3 & 6 & 1,248 & 17 & $1.4(0.9-2.2)$ & 0 & $0.0(0.0-0.2)$ & 24 & $1.9(1.3-2.8)$ \\
\hline $\mathrm{T}$ & 23 & 603 & 98 & 3 & 5 & 1,560 & 17 & $1.1(0.7-1.7)$ & 0 & $0.0(0.0-0.2)$ & 25 & $1.6(1.1-2.3)$ \\
\hline U & 24 & 613 & 98 & 4 & 9 & 2,378 & 88 & 3.7 (3.0-4.5) & 0 & $0.0(0.0-0.1)$ & 52 & $2.2(1.7-2.8)$ \\
\hline V & 25 & 689 & 99 & 4 & 7 & 2,495 & 41 & $1.6(1.2-2.2)$ & 1 & $0.0(0.0-0.2)$ & 41 & $1.6(1.2-2.2)$ \\
\hline W & 26 & 469 & 98 & 6 & 9 & 2,580 & 7 & $0.3(0.1-0.5)$ & 0 & $0.0(0.0-0.1)$ & 11 & $0.4(0.2-0.7)$ \\
\hline$X$ & 27 & 1019 & 100 & 3 & 9 & 2,730 & 26 & $1.0(0.6-1.4)$ & 2 & $0.1(0.0-0.2)$ & 47 & $1.7(1.3-2.3)$ \\
\hline$Y$ & 28 & 771 & 100 & 4 & 8 & 3,176 & & & 1 & $0.0(0.0-0.1)$ & 22 & $0.7(0.5-1.0)$ \\
\hline Total & & 5471 & & & & 19,141 & 254 & 1.59 & 4 & 0.02 & 277 & 1.45 \\
\hline
\end{tabular}

model and their 95\% CIs from the regression models are given. None of the HRs for thromboembolism or bleeding were significantly different from 1 (the $95 \%$ CIs contained the value 1 ). In the aortic position, the Carbomedics valve had less valve thrombosis (HR 0.16) and the 95\% CI (0.06$0.56)$ excluded the value 1 . In the mitral position, the Carbomedics valve had more valve thrombosis (HR 1.94) and the 95\% CI (0.98-3.84) almost excluded the value 1 .

We used three series-level variables to try to adjust for some of the variation between valves. Levels of anticoagulation could affect the results. But international normalized ratio values were not generally available for these series, and reviewers of an earlier draft wondered whether bleeding rate could be a surrogate for anticoagulation intensity. This did not turn out to be the case (Figure 7). In fact, there was a positive (rather than inverse) relationship between bleeding and both thromboembolism and valve thrombosis in both positions; in none of the regression models was the HR for bleeding rate less than unity, which would indicate a protective factor. So this was not considered further.

Another potentially important series-level factor was follow-up time (Figure 8). If the hazard decreases with time, then the Carbomedics series, with shorter follow-up on average, would be at a disadvantage. We allowed mean follow-up to enter every regression. In none of them was it significant $(P>.10)$, and in some its HR was greater than 1 , indicating increasing risk with longer follow-up. When the effect went in the "correct" direction, we forced it into the model, and it changed the results somewhat in favor of the Carbomedics valve. These results are also included in Table 5.

The final series-level factor considered in the regression models was follow-up completeness (Figure 9). It seems reasonable that more complete follow-up might result in 


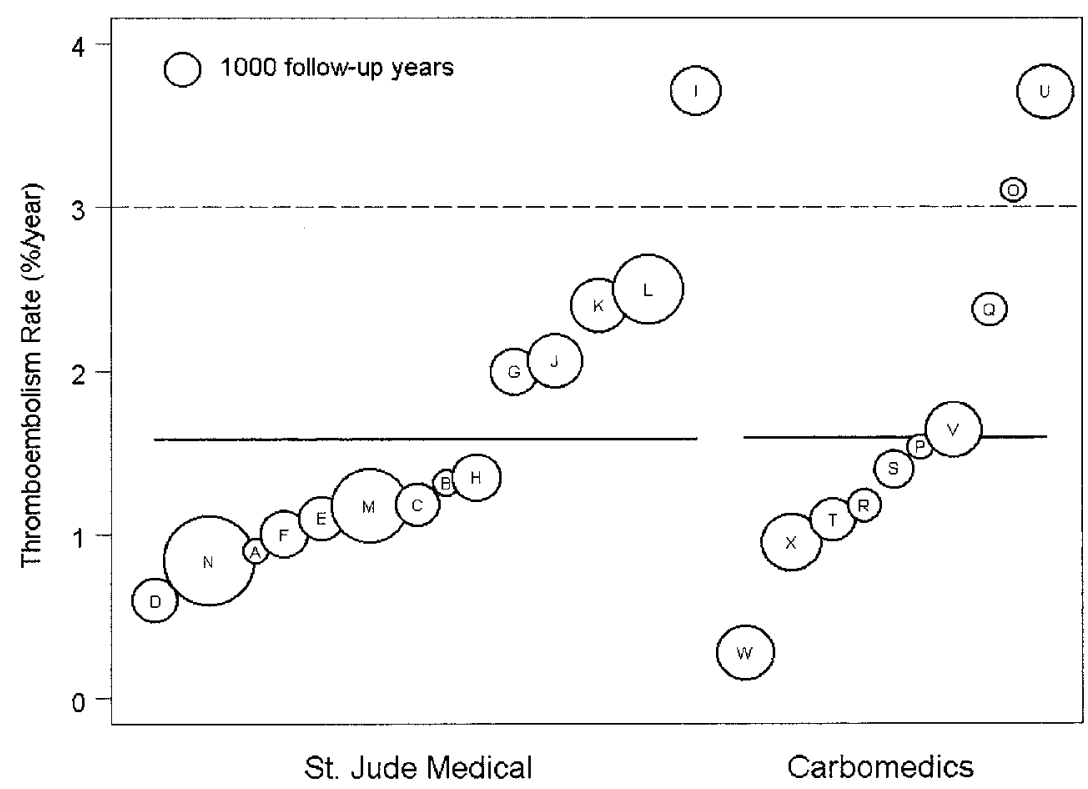

Figure 1. Thromboembolism (TE) rates for St Jude Medical and Carbomedics aortic valves. Each circle represents 1 series, with area of circle proportional to number of patient-years in series, as shown by calibration circle in upper left. Solid horizontal lines represent weighted average for each valve model. Horizontal dashed line $(3.0 \% / y)$ represents Food and Drug Administration's objective performance criterion (OPC) for new valve approvals.

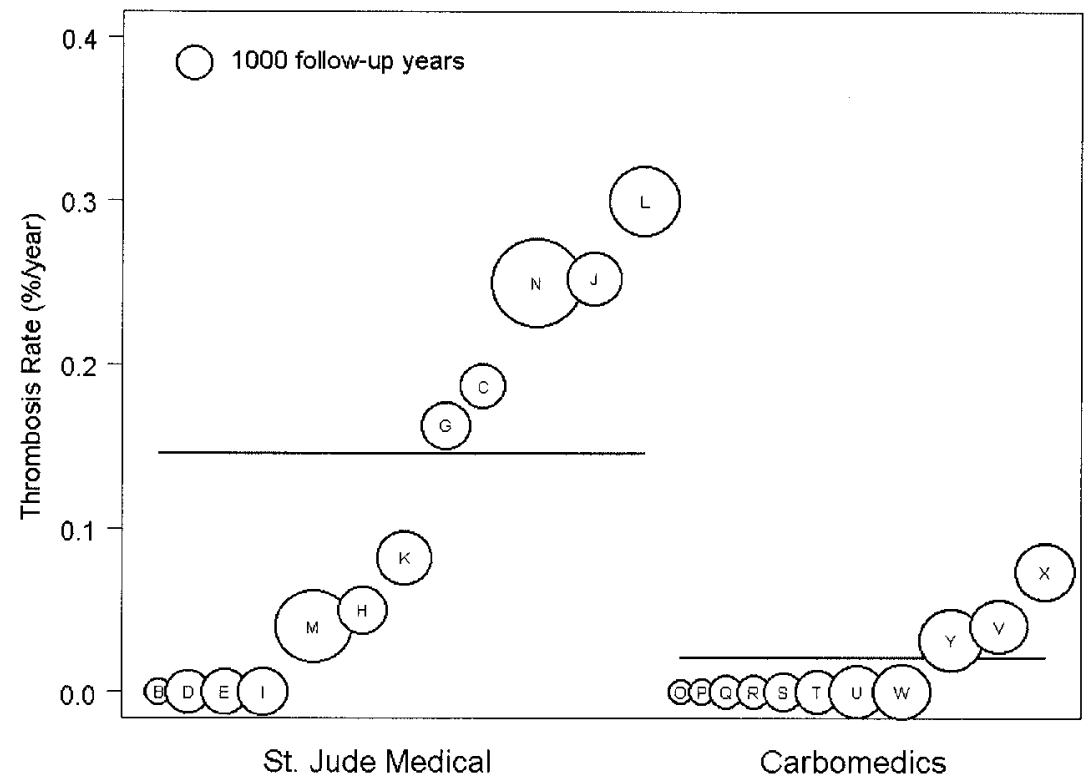

Figure 2. Thrombosis rates for St Jude Medical and Carbomedics aortic valves. Each circle represents 1 series, with area of circle proportional to number of patient-years in series, as shown by calibration circle in upper left. Solid horizontal lines represent weighted averages for each valve model. The Food and Drug Administration's criterion for new valve approvals $(0.8 \% / y)$ is not shown on this graph.

higher event rates. Thus we allowed follow-up percentage to enter every model. It was never close to significant, and only in three models was its HR greater than 1 (meaning higher percentage associated with higher event rate). When forced into these three models, it made only the slightest change, at most 0.02 decrease in the HR for valve model. 


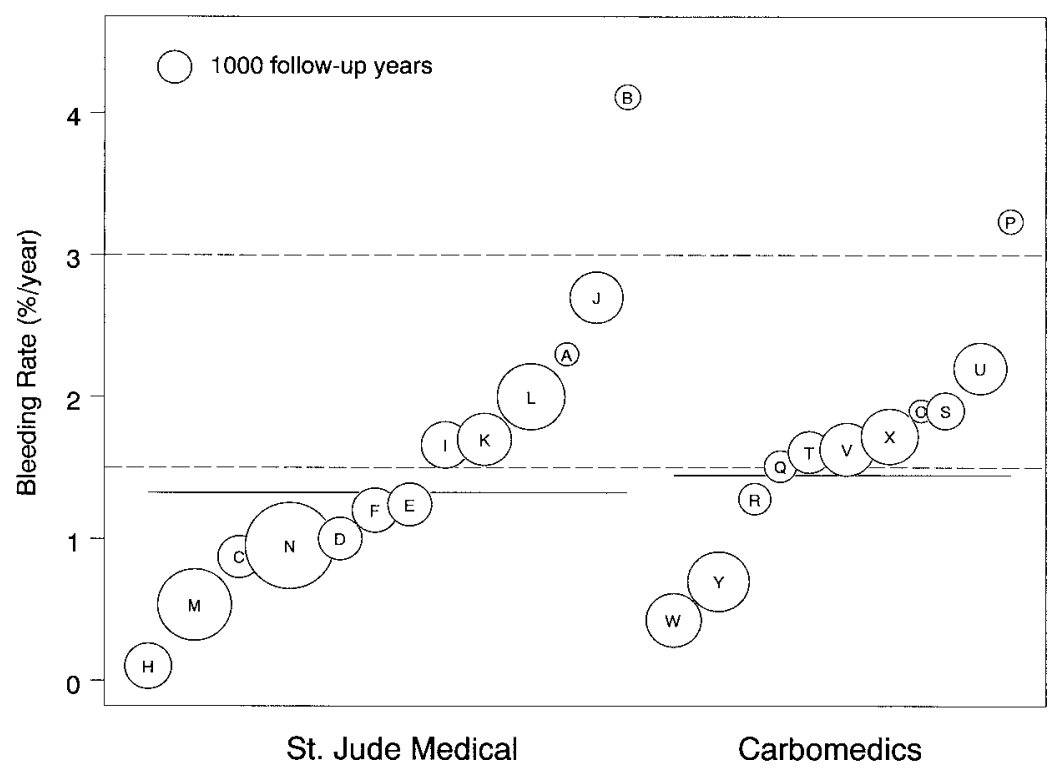

Figure 3. Bleeding rates for St Jude Medical and Carbomedics aortic valves. Each circle represents 1 series, with area of circle proportional to number of patient-years in series, as shown by calibration circle in upper left. Solid horizontal lines represent weighted averages for each valve model. Horizontal dashed lines represent Food and Drug Administration's criteria for major bleeding (1.5\%/y) and all bleeding (3.0\%/y).

TABLE 3. St. Jude Medical mitral valves

\begin{tabular}{|c|c|c|c|c|c|c|c|c|c|c|c|c|}
\hline \multirow[b]{3}{*}{ Series } & \multirow[b]{3}{*}{ Reference } & \multirow[b]{3}{*}{ Valves } & \multicolumn{4}{|c|}{ Follow-up } & \multirow{2}{*}{\multicolumn{2}{|c|}{ Thromboembolism }} & \multirow{2}{*}{\multicolumn{2}{|c|}{ Thrombosis }} & \multirow{2}{*}{\multicolumn{2}{|c|}{ Bleeding }} \\
\hline & & & \multirow{2}{*}{$\begin{array}{c}\text { Complete } \\
(\%)\end{array}$} & \multirow{2}{*}{$\begin{array}{l}\text { Mean } \\
\text { (y) }\end{array}$} & \multirow{2}{*}{$\begin{array}{l}\text { Longest } \\
\text { (y) }\end{array}$} & \multirow{2}{*}{$\begin{array}{l}\text { Total } \\
\text { (pt-y) }\end{array}$} & & & & & & \\
\hline & & & & & & & Events & Rate $(95 \% \mathrm{CI})$ & Events & Rate $(95 \%$ CI) & Events & Rate $(95 \% \mathrm{Cl})$ \\
\hline$A$ & 11 & 94 & 96 & 9 & 15 & 869 & 25 & $2.9(1.9-4.2)$ & 0 & $0.0(0.0-0.3)$ & & \\
\hline$B$ & 29 & 385 & 99 & 2 & 5 & 926 & 47 & $5.1(3.8-6.7)$ & 3 & $0.3(0.1-0.9)$ & 8 & $0.9(0.4-1.6)$ \\
\hline C & 8 & 166 & 97 & 6 & 13 & 930 & 3 & $0.3(0.1-0.9)$ & 1 & $0.1(0.0-0.5)$ & 11 & $1.2(0.6-2.0)$ \\
\hline$D$ & 7 & 490 & 98 & 3 & 10 & 1,287 & 42 & $3.3(2.4-4.4)$ & 4 & $0.3(0.1-0.7)$ & 15 & $1.2(0.7-1.9)$ \\
\hline $\mathrm{E}$ & 13 & 163 & 100 & 9 & 10 & 1,520 & 78 & $5.1(4.1-6.4)$ & 1 & $0.1(0.0-0.3)$ & 28 & $1.8(1.3-2.6)$ \\
\hline $\mathrm{F}$ & 18 & 207 & 95 & 8 & 15 & 1,580 & 28 & $1.8(1.2-2.5)$ & 7 & $0.4(0.2-0.9)$ & 14 & $0.9(0.5-1.4)$ \\
\hline $\mathrm{G}$ & 15 & 440 & 100 & 4 & 12 & 1,782 & 78 & $4.4(3.5-5.5)$ & 2 & $0.1(0.0-0.4)$ & 50 & $2.8(2.1-3.7)$ \\
\hline $\mathrm{H}$ & 14 & 292 & 97 & 6 & 16 & 1,868 & 63 & $3.4(2.6-4.3)$ & 1 & $0.1(0.0-0.3)$ & 29 & $1.6(1.1-2.2)$ \\
\hline I & 16 & 513 & 97 & 5 & 20 & 2,662 & 77 & $2.9(2.3-3.6)$ & 5 & $0.2(0.1-0.4)$ & 51 & $1.9(1.4-2.5)$ \\
\hline $\mathrm{J}$ & 12 & 636 & 98 & 5 & 12 & 3,252 & 53 & $1.6(1.2-2.1)$ & 3 & $0.1(0.0-0.2)$ & 6 & $0.2(0.1-0.4)$ \\
\hline $\mathrm{K}$ & 30 & 440 & 98 & 11 & 19 & 4,877 & 34 & $0.7(0.5-1.0)$ & 10 & $0.2(0.1-0.4)$ & 49 & $1.0(0.8-1.3)$ \\
\hline Total & & 3826 & & & & 21,553 & 528 & 2.45 & 37 & 0.17 & 261 & 1.26 \\
\hline
\end{tabular}

\section{Discussion}

Comparing complication rates between established, clinically acceptable heart valves would be an ideal task for a randomized study. However, there are major implementation difficulties with such studies. They are extremely resource intensive, requiring many years and many valves to complete. The AVERT study of the St Jude Medical Silzone valve, designed to distinguish a 50\% reduction in endocarditis rates, required 4400 valves and 4 years' time to complete. $^{32}$ The major heart valve randomized studies have taken so long to conduct that the valves originally entered into the study were no longer in use when the study was finished. ${ }^{33}$ And the results of those studies only confirmed what was already known from published observational studies.

Thus observational studies provide almost all of the known valve complication information. However, observational studies have an important disadvantage. When a randomized study is begun, its existence is generally announced, and the results eventually become available. However, most reports of observational studies are ad hoc; the decision to publish is usually made after the data are collected and analyzed and the results are known. Thus the series reported in the literature may not be representative of 


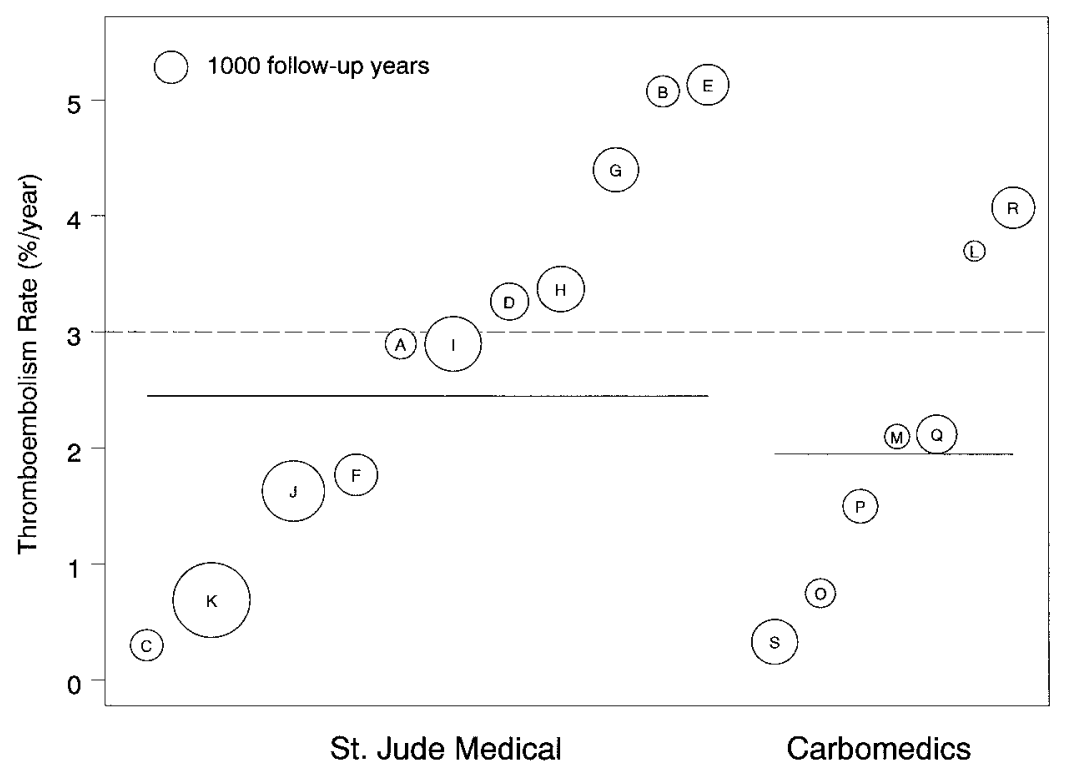

Figure 4. Thromboembolism rates for St Jude Medical and Carbomedics mitral valves. Each circle represents 1 series, with area of circle proportional to number of patient-years in series, as shown by calibration circle in upper left. Solid horizontal lines represent weighted averages for each valve model. Horizontal dashed line (3.0\%/y) represents Food and Drug Administration's objective performance criterion for new valve approvals.

TABLE 4. Carbomedics mitral valves

\begin{tabular}{|c|c|c|c|c|c|c|c|c|c|c|c|c|}
\hline \multirow[b]{3}{*}{ Series } & \multirow[b]{3}{*}{ Reference } & \multirow[b]{3}{*}{ Valves } & \multicolumn{4}{|c|}{ Follow-up } & \multirow{2}{*}{\multicolumn{2}{|c|}{ Thromboembolism }} & \multirow{2}{*}{\multicolumn{2}{|c|}{ Thrombosis }} & \multirow{2}{*}{\multicolumn{2}{|c|}{ Bleeding }} \\
\hline & & & \multirow{2}{*}{$\begin{array}{c}\text { Complete } \\
(\%)\end{array}$} & \multirow{2}{*}{$\begin{array}{c}\text { Mean } \\
\text { (y) }\end{array}$} & \multirow{2}{*}{$\begin{array}{l}\text { Longest } \\
\text { (y) }\end{array}$} & \multirow{2}{*}{$\begin{array}{l}\text { Total } \\
\text { (pt-y) }\end{array}$} & & & & & & \\
\hline & & & & & & & Events & Rate $(95 \% \mathrm{CI})$ & Events & Rate $(95 \% \mathrm{CI})$ & Events & Rate $(95 \% \mathrm{Cl})$ \\
\hline L & 19 & 189 & 97 & 2 & 5 & 431 & 16 & $3.7(2.2-5.9)$ & 2 & $0.5(0.1-1.5)$ & 12 & $2.8(1.5-4.7)$ \\
\hline$M$ & 22 & 167 & 98 & 3 & 6 & 580 & 12 & $2.1(1.1-3.5)$ & 2 & $0.3(0.1-1.1)$ & 9 & $1.6(0.8-2.8)$ \\
\hline $\mathrm{N}$ & 28 & 169 & 100 & 4 & 8 & 677 & & & 3 & $0.4(0.1-1.2)$ & 2 & $0.3(0.1-1.0)$ \\
\hline 0 & 20 & 167 & 99 & 5 & 8 & 800 & 6 & $0.8(0.3-1.5)$ & 0 & $0.0(0.0-0.3)$ & 7 & $0.9(0.4-1.7)$ \\
\hline$P$ & 25 & 328 & 99 & 3 & 7 & 1096 & 16 & $1.5(0.9-2.3)$ & 2 & $0.2(0.0-0.6)$ & 25 & $2.3(1.5-3.3)$ \\
\hline 0 & 31 & 428 & 100 & 3 & 5 & 1398 & 30 & $2.1(1.5-3.0)$ & 7 & $0.5(0.2-1.0)$ & 21 & $1.5(1.0-2.3)$ \\
\hline $\mathrm{R}$ & 24 & 447 & 98 & 4 & 9 & 1571 & 64 & $4.1(3.2-5.2)$ & 11 & $0.7(0.4-1.2)$ & 37 & $2.3(1.7-3.2)$ \\
\hline$S$ & 26 & 330 & 98 & 6 & 9 & 1815 & 6 & $0.3(0.1-0.7)$ & 1 & $0.1(0.0-0.3)$ & 5 & $0.3(0.1-0.6)$ \\
\hline Total & & 2225 & & & & 8368 & 150 & 1.95 & 28 & 0.33 & 118 & 1.41 \\
\hline
\end{tabular}

the experience in general. And this publication bias may occur preferentially when the outcomes are either favorable or unfavorable. This phenomenon has been recently demonstrated for the outcome of operative mortality after cardiac surgery. ${ }^{34}$

We have previously compiled reviews of published valve complication rates and used graphic techniques to compare them visually, but we refrained from performing formal analytical comparisons because of the great variability among series. ${ }^{35,36} \mathrm{We}$ therefore did not produce weighted average rates for each model, either to characterize a particular model or to make comparisons between valve models. These comparisons were purely descriptive, not inferential.
However, it is natural to pool the results across many studies of the same valve and try to draw an overall conclusion regarding complication rates, and some have done so through simple comparison of the pooled means. This study found significant heterogeneity among 10 of the 12 subgroups of event rates (Table 5). This implies that simple pooled (weighted average) rates cannot be compared directly. The reasons for the heterogeneity could include patient-specific risk factors (many are known) and centerspecific factors (postoperative management and data collection methods). To this list would have been added "event definitions"; however, all these reports claim to adhere to the guidelines for reporting.

It has been claimed that thromboembolism is predomi- 


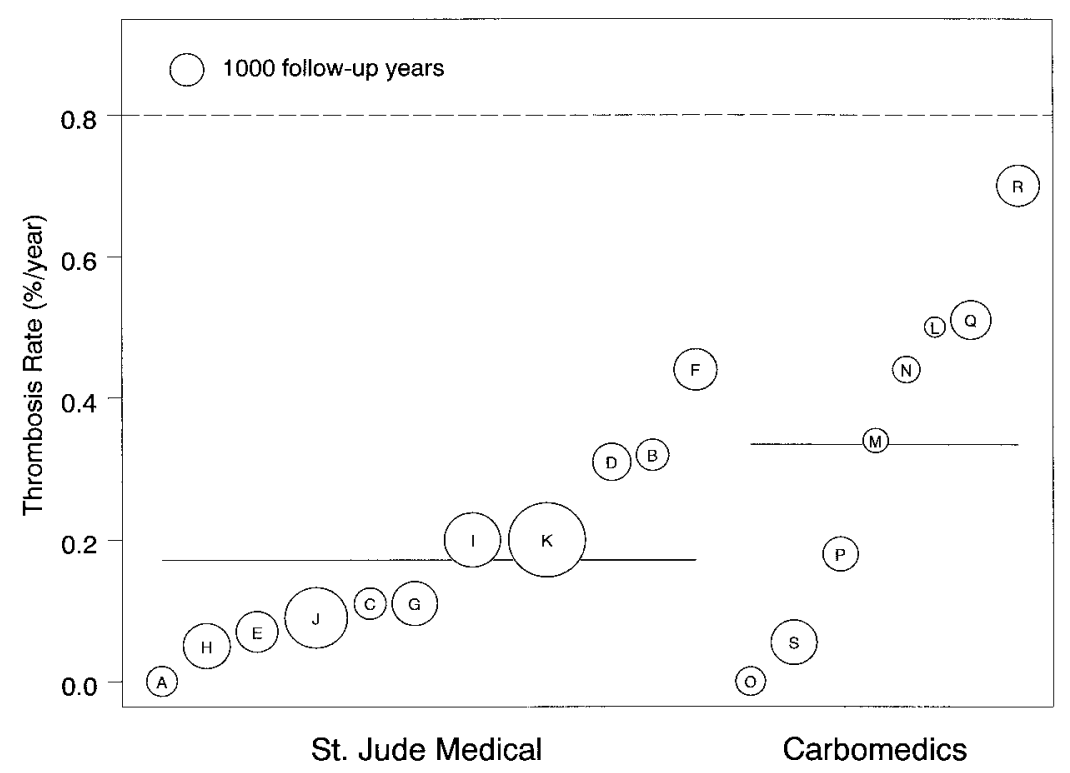

Figure 5. Thrombosis rates for St Jude Medical and Carbomedics mitral valves. Each circle represents 1 series, with area of circle proportional to number of patient-years in series, as shown by calibration circle in upper left. Solid horizontal lines represent weighted averages for each valve model. Horizontal dashed line $(0.8 \% / y)$ represents Food and Drug Administration's objective performance criterion for new valve approvals.

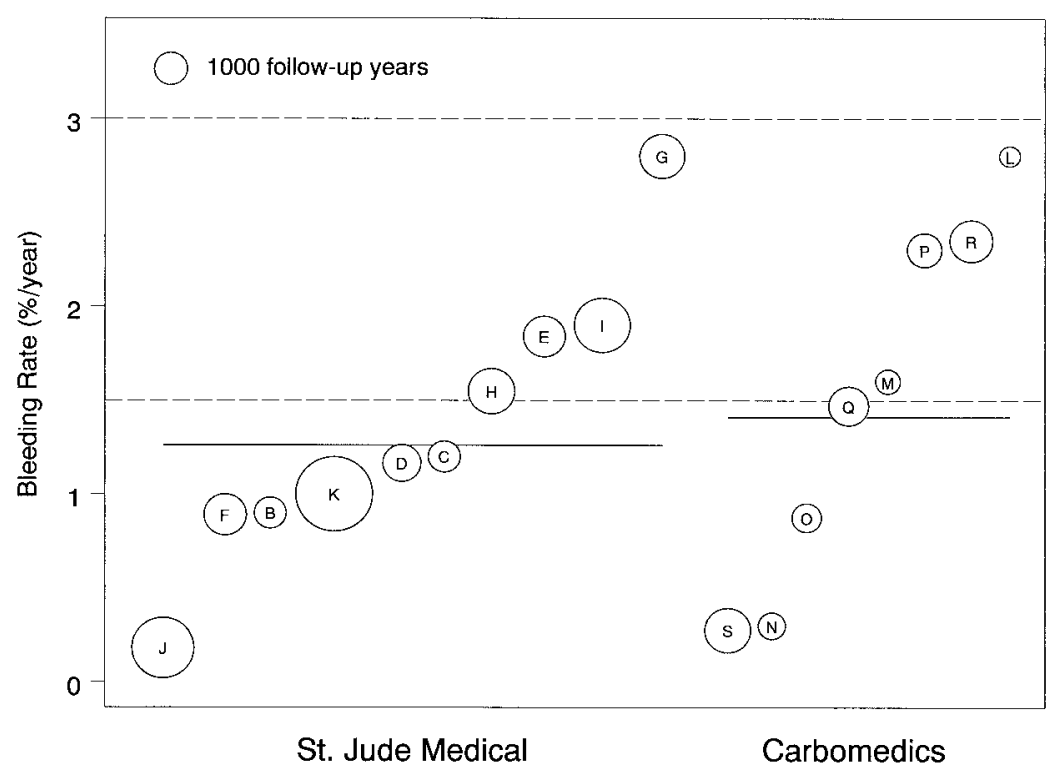

Figure 6. Bleeding rates for St Jude Medical and Carbomedics mitral valves. Each circle represents 1 series, with area of circle proportional to number of patient-years in series, as shown by calibration circle in upper left. Solid horizontal lines represent weighted averages for each valve model. Horizontal dashed lines represent Food and Drug Administration's criteria for major bleeding (1.5\%/y) and all bleeding (3.0\%/y).

nantly patient related, whereas thrombosis is more indicative of prosthesis function. ${ }^{37}$ In this study the two valve models had similar thromboembolism and bleeding rates in both positions, but valve thrombosis rates were different. In the mitral position the Carbomedics valve's rate was higher, as has been alluded to by some previous studies. $24,38,39$ There was a significantly lower valve thrombosis rate in the aortic position with the Carbomedics valve. Because thrombosis rates themselves are low, however, the differences between them (rather than the ratios) are extremely small, 
Aortic TE by Bleed

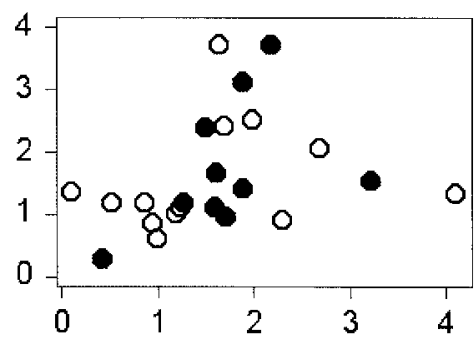

Aortic VT by Bleed

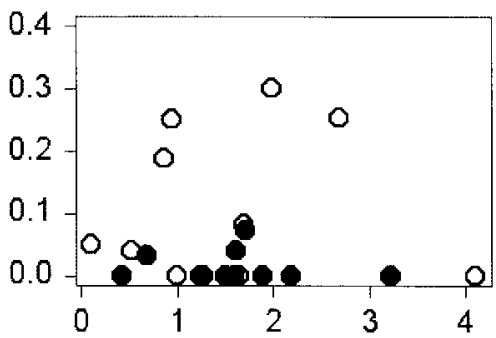

Mitral TE by Bleed

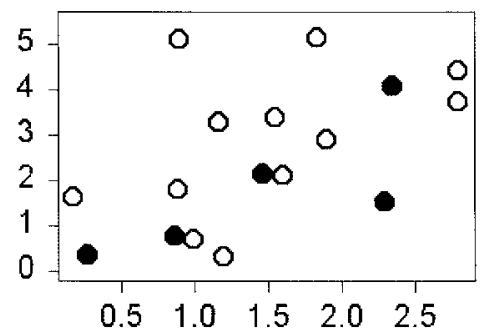

Mitral VT by Bleed

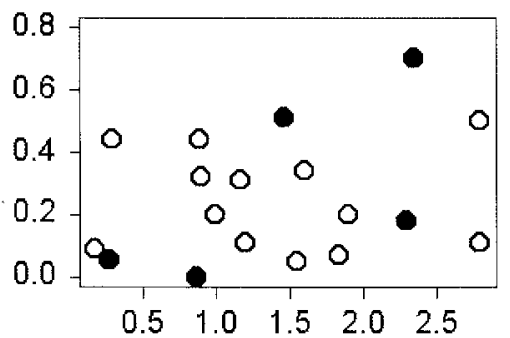

Figure 7. Relationship of thromboembolism (TE) and valve thrombosis (VT) rates (in percent per year, on vertical axes) to bleeding rates (in percent per year, on horizontal axes). Open circles indicate St Jude Medical series and filled circles indicate Carbomedics series.

TABLE 5. Pooled event rates and HRs for comparison of event rates

\begin{tabular}{|c|c|c|c|c|c|c|c|}
\hline \multirow[b]{2}{*}{ Event } & \multirow[b]{2}{*}{ Valve } & \multicolumn{2}{|c|}{ Pooled event rates } & \multicolumn{2}{|c|}{ Valve only in model } & \multicolumn{2}{|c|}{ Mean follow-up forced in } \\
\hline & & Rate $(\% / y)$ & Cochran* $P$ value & HRT & $95 \% \mathrm{Cl}$ & HRT & $95 \%$ CI \\
\hline \multicolumn{8}{|l|}{ Aortic position } \\
\hline \multirow[t]{2}{*}{ Thromboembolism } & St Jude & 1.58 & $<.001$ & 1.06 & $0.68-1.66$ & & \\
\hline & Carbomedics & 1.59 & $<.001$ & & & & \\
\hline \multirow[t]{2}{*}{ Valve thrombosis } & St Jude & 0.14 & .005 & 0.16 & $0.05-0.56$ & & \\
\hline & Carbomedics & 0.02 & .777 & & & & \\
\hline \multirow{2}{*}{ Bleeding } & St Jude & 1.32 & $<.001$ & 1.06 & $0.66-1.70$ & 0.98 & $0.55-1.76$ \\
\hline & Carbomedics & 1.45 & $<.001$ & & & & \\
\hline \multicolumn{8}{|l|}{ Mitral position } \\
\hline \multirow[t]{2}{*}{ Thromboembolism } & St Jude & 2.45 & $<.001$ & 0.72 & $0.38-1.38$ & 0.54 & $0.27-1.09$ \\
\hline & Carbomedics & 1.95 & $<.001$ & & & & \\
\hline \multirow[t]{2}{*}{ Valve thrombosis } & St Jude & 0.17 & .111 & 1.94 & $0.98-3.84$ & 1.58 & $0.73-3.41$ \\
\hline & Carbomedics & 0.33 & .03 & & & & \\
\hline \multirow{2}{*}{ Bleeding } & St Jude & 1.26 & $<.001$ & 1.1 & $0.60-2.00$ & 0.94 & $0.49-1.83$ \\
\hline & Carbomedics & 1.41 & $<.001$ & & & & \\
\hline
\end{tabular}

*Heterogeneity among series was tested with Cochran test.

tHR for valve model effect of Carbomedics valve.

representing an incidence of fewer than 2 thromboses in 1000 patient-y. This may be a situation where statistical significance, if it exists, does not imply a clinically important difference.

The findings of this study must be viewed with caution. We have stressed the statistical limitations of combining and comparing diverse valve series. There are also limitations related to data collection (Appendix 1) and definitions.
For example, we attempted to adjust for intensity of follow-up by incorporating follow-up completeness in the models. However, completeness of follow-up may be a poor surrogate for follow-up intensity. There is a difference between a prospectively oriented follow-up system, in which patients are periodically contacted from their surgical dates forward, and a retrospective approach, where patients may be contacted for the first time perhaps 10 years after the 
Aortic TE by Mean FU

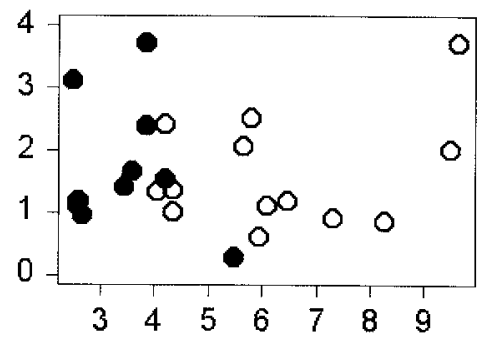

Aortic VT by Mean FU

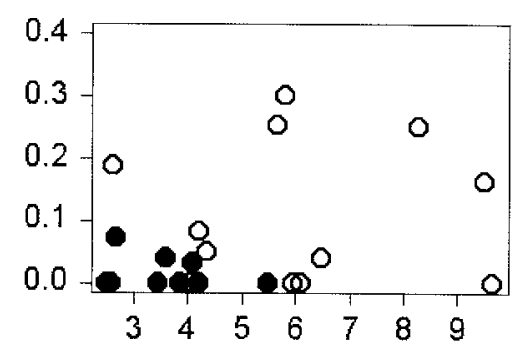

Mitral TE by Mean FU

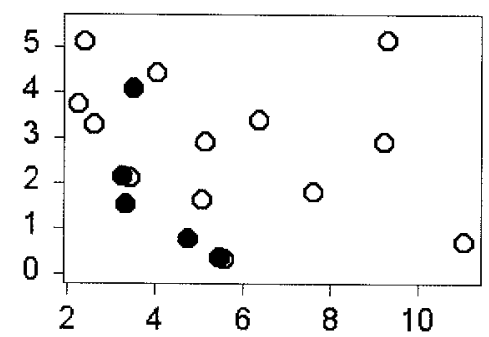

Mitral VT by Mean FU

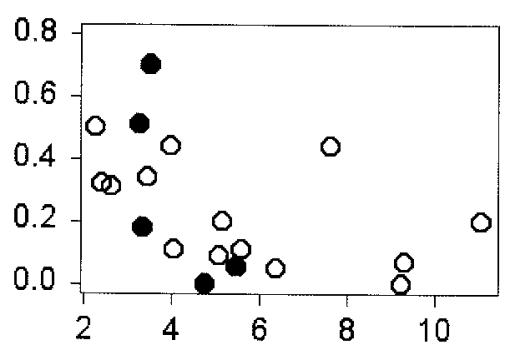

Figure 8. Relationship of thromboembolism (TE) and valve thrombosis (VT) rates (in percent per year, on vertical axes) to mean follow-up ( $F U$, in years, on horizontal axes). Open circles indicate St Jude Medical series and filled circles indicate Carbomedics series.
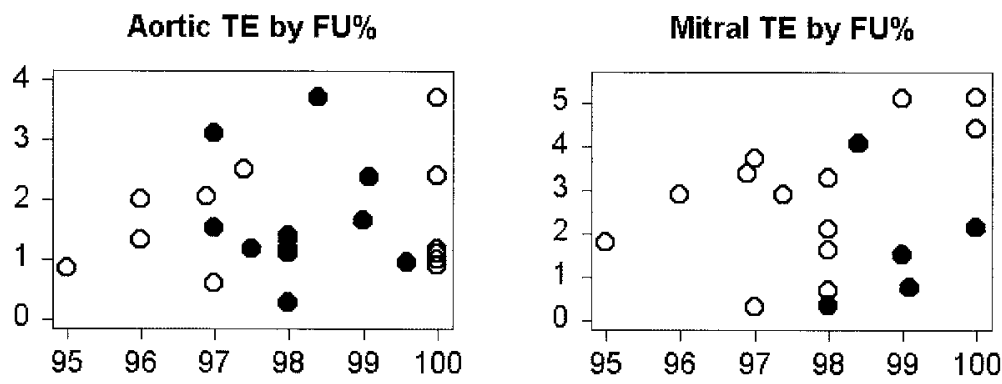

Aortic VT by FU\%

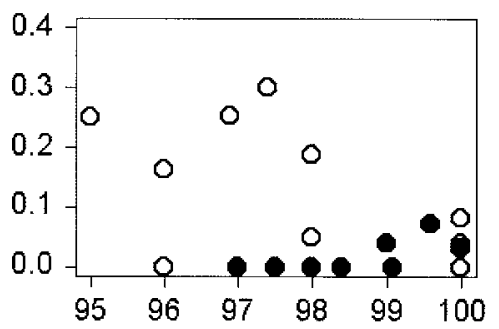

Mitral VT by FU\%

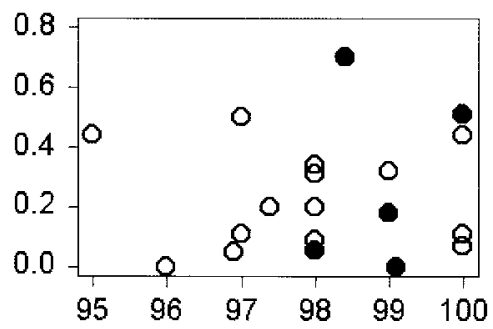

Figure 9. Relationship of thromboembolism (TE) and valve thrombosis (VT) rates (in percent per year on vertical axes) to completeness of follow-up ( $F U$, in percent, on horizontal axes). Open circles indicate St Jude Medical series and filled circles indicate Carbomedics series.

operation. Thus even though a retrospective and a prospective series might have the same overall percentage of completeness, the one with a retrospective approach is much less likely to reveal intervening events, especially nonfatal ones, than is the one with a prospective approach. We tried to incorporate heterogeneity among series into our analyses 
but were still unable to explain this heterogeneity. With so many factors able to influence the results from different centers, it is difficult to combine analyses across different studies on the basis of published results.

Four journal referees provided thoughtful and constructive reviews of earlier drafts of this article and were responsible for several improvements in its scope and focus.

\section{References}

1. Division of Cardiovascular and Neurological Devices, Center for Devices and Radiological Health, Food and Drug Administration. Draft replacement heart valve guidance, version 4.1. 1994. http:// www.fda.gov/cdrh/ode/3751.html.

2. Edmunds LH Jr, Cohn LH, Weisel RD. Guidelines for reporting morbidity and mortality after cardiac valvular operations. $J$ Thorac Cardiovasc Surg. 1988;96:351-3.

3. Edmunds LH Jr, Clark RE, Cohn LH, Grunkemeier GL, Miller DC, Weisel RD. Guidelines for reporting morbidity and mortality after cardiac valvular operations. J Thorac Cardiovasc Surg. 1996;112:70811.

4. Cox DR. Some simple approximate test for Poisson variates. Biometrika. 1953;40:354-60.

5. Myken PS, Caidahl K, Larsson P, Larsson S, Wallentin I, Berggren HE. Mechanical versus biological valve prosthesis: a ten-year comparison regarding function and quality of life. Ann Thorac Surg. 1995;60(2 Suppl):S447-52.

6. Lim KH, Caputo M, Ascione R, Wild J, West R, Angelini GD, et al. Prospective randomized comparison of CarboMedics and St Jude Medical bileaflet mechanical heart valve prostheses: an interim report. J Thorac Cardiovasc Surg. 2002;123:21-32.

7. Fernandez J, Laub GW, Adkins MS, Anderson WA, Chen C, Bailey $\mathrm{BM}$, et al. Early and late-phase events after valve replacement with the St Jude Medical prosthesis in 1200 patients. J Thorac Cardiovasc Surg. 1994;107:394-406.

8. Smith JA, Westlake GW, Mullerworth MH, Skillington PD, Tatoulis J. Excellent long-term results of cardiac valve replacement with the St Jude Medical valve prosthesis. Circulation. 1993;88(5 Pt 2):II49-54.

9. Sawant D, Singh AK, Feng WC, Bert AA, Rotenberg F. St Jude Medical cardiac valves in small aortic roots: follow-up to sixteen years. J Thorac Cardiovasc Surg. 1997;113:499-509.

10. Peterseim DS, Cen YY, Cheruvu S, Landolfo K, Bashore TM, Lowe JE, et al. Long-term outcome after biologic versus mechanical aortic valve replacement in 841 patients. J Thorac Cardiovasc Surg. 1999; 117:890-7.

11. Debetaz LF, Ruchat P, Hurni M, Fischer A, Stumpe F, Sadeghi H, et al. St Jude Medical valve prosthesis: an analysis of long-term outcome and prognostic factors. J Thorac Cardiovasc Surg. 1997;113:134-48.

12. Nakano K, Koyanagi H, Hashimoto A, Kitamura M, Endo M, Nagashima M, et al. Twelve years' experience with the St Jude Medical valve prosthesis. Ann Thorac Surg. 1994;57:697-702.

13. Horstkotte D, Schulte H, Bircks W, Strauer B. Unexpected findings concerning thromboembolic complications and anticoagulation after complete 10 year follow up of patients with St Jude Medical prostheses. J Heart Valve Dis. 1993;2:291-301.

14. Zellner JL, Kratz JM, Crumbley AJ 3rd, Stroud MR, Bradley SM, Sade RM, et al. Long-term experience with the St Jude Medical valve prosthesis. Ann Thorac Surg. 1999;68:1210-8.

15. Ibrahim MO, Kane H, Cleland J, Gladstone D, Sarsam M, Patterson C. The St Jude Medical prosthesis: a thirteen-year experience. J Thorac Cardiovasc Surg. 1994;108:221-30.

16. Khan SS, Trento A, DeRobertis M, Kass RM, Sandhu M, Czer LS, et al. Twenty-year comparison of tissue and mechanical valve replacement. J Thorac Cardiovasc Surg. 2001;122:257-69.

17. Lund O, Nielsen SL, Arildsen H, Ilkjaer LB, Pilegaard HK. Standard aortic St Jude valve at 18 years: performance profile and determinants of outcome. Ann Thorac Surg. 2000;69:1459-65.
18. Baudet EM, Puel V, McBride JT, Grimaud JP, Roques F, Clerc F, et al. Long-term results of valve replacement with the St Jude Medical prosthesis. J Thorac Cardiovasc Surg. 1995;109:858-70.

19. Nistal JF, Hurle A, Revuelta JM, Gandarillas M. Clinical experience with the CarboMedics valve: early results with a new bileaflet mechanical prosthesis. J Thorac Cardiovasc Surg. 1996;112:59-68.

20. Soga Y, Okabayashi H, Nishina T, Enomoto S, Shimada I, Miyamoto TA, et al. Up to 8-year follow-up of valve replacement with Carbomedics valve. Ann Thorac Surg. 2002;73:474-9.

21. Knez I, Machler H, Rehak P, Oberwalder P, Anelli-Monti M, Dacar D, et al. Concomitant procedures in the small versus standard aortic root. J Heart Valve Dis. 1996;5 Suppl 3:S294-301.

22. Rodler SM, Moritz A, Schreiner W, End A, Dubsky P, Wolner E. Five-year follow-up after heart valve replacement with the CarboMedics bileaflet prosthesis. Ann Thorac Surg. 1997;63:1018-25.

23. Copeland JG 3rd. An international experience with the CarboMedics prosthetic heart valve. J Heart Valve Dis. 1995;4:56-62.

24. Jamieson WR, Fradet GJ, Miyagishima RT, Henderson C, Brownlee RT, Zhang J, et al. CarboMedics mechanical prosthesis: performance at eight years. $J$ Heart Valve Dis. 2000;9:678-87.

25. Dalrymple-Hay MJ, Pearce R, Dawkins S, Haw MP, Lamb RK, Livesey SA, et al. A single-center experience with 1,378 CarboMedics mechanical valve implants. Ann Thorac Surg. 2000;69:457-63.

26. Santini F, Casali G, Viscardi F, Favaro A, Luciani GB, Pentiricci S, et al. The Carbomedics prosthetic heart valve: experience with 1,084 implants. J Heart Valve Dis. 2002;11:121-6.

27. Li HH, Hahn J, Urbanski P, Torka M, Grunkemeier GL, Hacker RW. Intermediate-term results with 1,019 Carbomedics aortic valves. Ann Thorac Surg. 2001;71:1181-7.

28. Fiane AE, Geiran OR, Svennevig JL. Up to eight years' follow-up of 997 patients receiving the CarboMedics prosthetic heart valve. Ann Thorac Surg. 1998;66:443-8.

29. Jamieson WR, Miyagishima RT, Grunkemeier GL, Germann E, Henderson C, Fradet GJ, et al. Bileaflet mechanical prostheses performance in mitral position. Eur J Cardiothorac Surg. 1999;15:786-94.

30. Remadi JP, Baron O, Roussel C, Bizouarn P, Habasch A, Despins P, et al. Isolated mitral valve replacement with St Jude Medical prosthesis: long-term results: a follow-up of 19 years. Circulation. 2001;103: $1542-5$.

31. Copeland JG. The CarboMedics prosthetic heart valve in the mitral position: results of the multicenter international trial. J Card Surg. 1997;12:205-9.

32. Schaff H, Carrel T, Steckelberg JM, Grunkemeier GL, Holubkov R. Artificial Valve Endocarditis Reduction Trial (AVERT): protocol of a multicenter randomized trial. J Heart Valve Dis. 1999;8:131-9.

33. Bloomfield P, Wheatley DJ, Prescott RJ, Miller HC. Twelve-year comparison of a Bjork-Shiley mechanical heart valve with porcine bioprostheses. N Engl J Med. 1991;324:573-9.

34. Anyanwu AC, Treasure T. Unrealistic expectations arising from mortality data reported in the cardiothoracic journals. $J$ Thorac Cardiovasc Surg. 2002;123:16-20.

35. Grunkemeier GL, Starr A. Alternatives to randomization in surgical studies. J Heart Valve Dis. 1992;1:142-51.

36. Grunkemeier GL, Li HH, Naftel DC, Starr A, Rahimtoola SH. Longterm performance of heart valve prostheses. Curr Probl Cardiol. 2000;25:73-154.

37. Butchart EG, Li HH, Payne N, Buchan K, Grunkemeier GL. Twenty years' experience with the Medtronic Hall valve. J Thorac Cardiovasc Surg. 2001;121:1090-100.

38. Rosengart TK, O'Hara M, Lang SJ, Ko W, Altorki N, Krieger KH, et al. Outcome analysis of 245 CarboMedics and St Jude valves implanted at the same institution. Ann Thorac Surg. 1998;66:1684-91.

39. Craver J. Carbomedics Prosthetic Heart Valve. Eur J Cardiothorac Surg. 1999;15 Suppl 1:S3-11.

40. Horstkotte D, Schulte HD, Bircks W, Strauer BE. Lower intensity anticoagulation therapy results in lower complication rates with the St Jude Medical prosthesis. J Thorac Cardiovasc Surg. 1994;107:113645.

41. Emery RW, Arom KV, Nicoloff DM. Utilization of the St Jude Medical prosthesis in the aortic position. Semin Thorac Cardiovasc Surg. 1996;8:231-6. 
42. Aoyagi S, Oryoji A, Nishi Y, Tanaka K, Kosuga K, Oishi K. Longterm results of valve replacement with the St Jude Medical valve. J Thorac Cardiovasc Surg. 1994;108:1021-9.

43. de la Fuente A, Sanchez R, Romero J, Berjon J, Imizcoz MA, Fernandez JL, et al. CarboMedics and Monostrut valves: clinical and hemodynamic outcomes in a randomized study. J Heart Valve Dis. 2000;9:303-7.

44. Aagaard J, Hansen CN, Tingleff J, Rygg I. Seven-and-a-half years clinical experience with the CarboMedics prosthetic heart valve. J Heart Valve Dis. 1995;4:628-33

45. Bernal JM, Rabasa JM, Gutierrez-Garcia F, Morales C, Nistal JF, Revuelta JM. The CarboMedics valve: experience with 1,049 implants. Ann Thorac Surg. 1998;65:137-43.

46. Lachin JM. Biostatistical methods. New York: John Wiley \& Sons; 2000.

47. Cochran W. Some methods of strengthening the common $\chi^{2}$ tests. Biometrics. 1954;10:417-51.

48. Venables WN, Ripley BD. Modern applied statistics with S-PLUS. New York: Springer-Verlag; 1997.

49. Schall R. Estimation in generalized linear models with random effects. Biometrika. 1991;78:719-27.

\section{Appendix 1}

\section{Data Limitations}

- There is a simple relationship between the linearized rate, the number of events, and the total follow-up years. We needed all three for the analysis, so if one of them was not given in the article, we derived it from the other two. If only one of the three was given, we did not use that article. If all three were given but were inconsistent with each other, we tried to determine the two most reliable values and recalculated the third.

- When total follow-up years were not given separately by position, we calculated them from the linearized rates and numbers of events if they were available. Otherwise we derived them as proportions of the total follow-up years according to the ratios of patients with each valve position.

- If thrombosis was included in the thromboembolism rate, we recalculated that rate to exclude the valve thromboses.

- One aortic Carbomedics series ${ }^{23}$ and 1 mitral Carbomedics series $^{31}$ were multicenter studies; publications from one of the investigators of those studies ${ }^{24,29}$ may include some overlap.

- One series defined late events as those occurring after 3 months ${ }^{40}$ and focused on anticoagulation management only, so we did not use that study.

- A few series were considered in the analyses but did not meet one of the selection criteria: 2 aortic series ${ }^{41,42}$ and 1 mitral series $^{42}$ had follow-up completeness between $92 \%$ and $94 \%$; 2 aortic series 28,43 included only major thromboembolic events, and 1 article did not mention adherence to the guidelines for reporting. 44
- Even though 1 Carbomedics reference ${ }^{45}$ appeared to update a previous reference, ${ }^{19}$ it did not separate thromboembolism by position, and the newer reference had fewer bleeding events because of a stricter definition of major bleeding.

\section{Appendix 2}

\section{Statistical Details}

If events occur independently at a constant rate of $R$ per patientyear, the number of events $E$ in $Y$ patient-years follows a Poisson distribution (with parameter $R Y$ ); the maximum likelihood estimate of $\mathrm{R}$ is $\mathrm{E} / \mathrm{Y}$. In the cardiac surgical literature this estimate is multiplied by 100 to convert it to events per 100 years, or percentage per year, and called the linearized rate.

If the rates in several series with the same valve are assumed to be equal, then their weighted average can be directly compared with, for example, a likelihood ratio test or an $F$ test, as suggested by Cox. ${ }^{4} \mathrm{~A}$ more general way to compare valve models when the rates among series with each model are similar is to use Poisson regression. ${ }^{46}$ Here the series are not directly pooled, and risk factors that differ among series can be incorporated to provide a HR for the effect of valve model adjusted for these other factors.

Before Poisson regression is used, however, series with the same valve model should be tested for homogeneity. A test for this could be a likelihood ratio test or the $\chi^{2}$ goodness-of-fit test attributed to Cochran. ${ }^{47}$ If there is significant heterogeneity among the rates for series with the same valve model, then Poisson regression should not be used directly, unless the heterogeneity can be accounted for by including other risk factors. If not, then a modification of simple Poisson regression can be used to account for the heterogeneity. One way is to use the negative binomial distribution. The negative binomial distribution is used to model count data from subgroups that have Poisson distributions but with differing rates that themselves have a gamma distribution. ${ }^{48}$ The negative binomial distribution is a generalization of the Poisson distribution in the sense that the variance of the negative binomial has an additional dispersion parameter; if this is 0 , the negative binomial collapses to the Poisson.

Another regression method is to include a random effect for medical center in the model to accommodate unmeasured variation that valves from the same center have in common but that may vary among different centers. ${ }^{49} \mathrm{We}$ used this method in several of the analyses but did not include the results because they were similar to those from the negative binomial regressions. The SPLUS 2000 statistical program (Insightful Corporation, Seattle, Wash) was used for all analyses. The S-PLUS functions used for Poisson, negative binomial, and random effect regressions were glm (generalized linear models), glm.nb (generalized linear model, negative binomial) and reglm (random effects generalized linear model), respectively. 